\title{
Generation of Pendant Amino Groups on Irradiation of Visible Light in the Presence of Benzoquinonylsulfanyl Derivatives
}

\author{
Kanji Suyama, Daisuke Natsui, Tadahiro Ohba, Masamitsu Shirai, and Masahiro Tsunooka \\ Department of Applied Chemistry, Osaka Prefecture University, \\ 1-1 Gakuen-cho, Sakai, Osaka 599-8531, Japan, suyama@chem.osakafu-u.ac.jp
}

Keywords: sensitizer, photobase generator, visible light, quinone, insolubilization, post-exposure bake

\section{INTRODUCTION}

The use of visible light is attractive for extending the fields of photocuring.[1] Usually, sensitizers are used in order to increase the sensitivity in visible region. However, the number of such sensitizers is limited, thus novel type of sensitizer is expected.

Benzoquinonylsulfanyl compounds have an absorbance band in the region of visible light.[2] We have reported that urethane oligomers bearing the benzoquinonylsulfanyl groups became insoluble on irradiation of visible light.[2,3]

On the other hand, it is known that pendant acyloxyimino (AOI) groups are transformed into primary amino groups on UV-irradiation as shown in Scheme 1.[4,5] Triplet sensitizers such as aromatic ketones are very effective for the phototransformation,[6] and benzoquinone and naphthoquinone were also effective.[7] Another base-

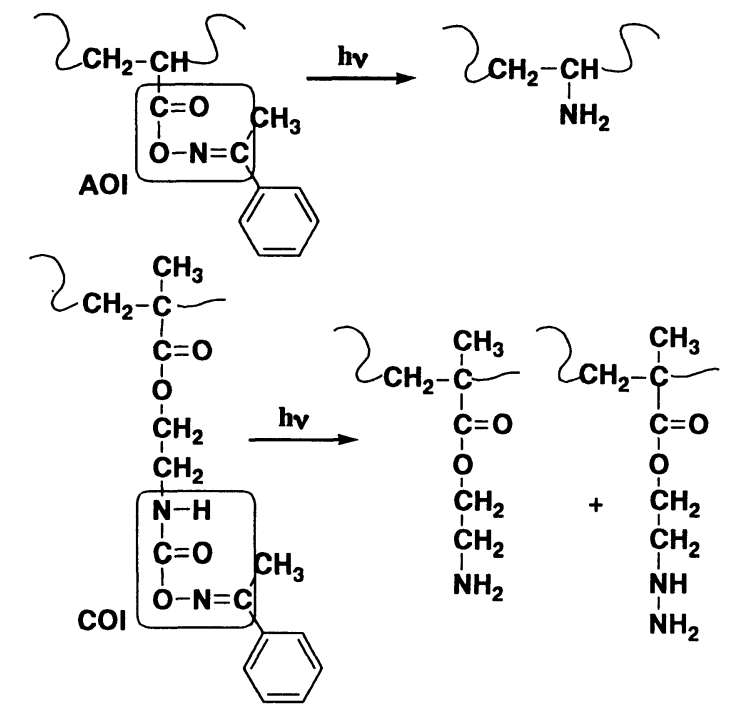

Scheme 1. Photoreactions of pendant AOI and COI groups. generating groups, carbamoyloxyimino(COI) groups, are also found to be transformed into amino and hydrazino groups on UV-irradiation.[810] Polymer films containing the generated basic groups became insoluble in THF after postexposure bake (PEB) treatment. $[10,11]$

In this communication, we report the visible light-sensitization of photolysis of pendant AOI and COI groups by benzoquinonylsulfanyl compounds and solubility change of polymer films containing them.

\section{EXPERIMENTAL}

IR, UV, and NMR spectral measurements were performed using a Jasco FTIR410, a Shimadzu 2400PC, and Jeol JNM-GX270 spectrometers, respectively. Elemental analyses were obtained on a Yanako MT-3 CHN Corder.

2-Benzylsulfanyl-1,4-benzoquinone (QBS) was prepared as described in literature.[2] Other quinone derivatives were also obtained from corresponding thiols and 1,4-benzoquinone.

2-Phenylsulfanyl-1,4-benzoquinone (QPhS): orange solid, $\mathrm{mp}=109-110{ }^{\circ} \mathrm{C}, \quad \mathrm{UV}\left(\mathrm{CH}_{3} \mathrm{CN}\right): \lambda_{\max }$ $=420 \mathrm{~nm}\left(\varepsilon=2400 \mathrm{~L} \cdot \mathrm{mol}^{-1} \cdot \mathrm{cm}^{-1}\right) ; \quad{ }^{1} \mathrm{H}-\mathrm{NMR}$ $\left(\mathrm{CDCl}_{3}\right): \delta=5.88(1 \mathrm{H}, \mathrm{d}, \mathrm{H}-3), 6.68(1 \mathrm{H}, \mathrm{dd}, \mathrm{J}=2.7$ and $9.7 \mathrm{~Hz}, \mathrm{H}-5), 6.83(1 \mathrm{H}, \mathrm{d}, \mathrm{H}-6), 7.42-7.60(5 \mathrm{H}$, $\mathrm{m}$, aromatic). ${ }^{13} \mathrm{C}-\mathrm{NMR}\left(\mathrm{CDCl}_{3}\right): \delta=125.87$, $126.84,130.38,130.61,135.63,135.84,137.45$, 154.33, 183.95, 184.45. Calcd for $\mathrm{C}_{12} \mathrm{H}_{8} \mathrm{O}_{2} \mathrm{~S}: \mathrm{C}$ 66.67, H 3.70. Found: C 67.26, H 3.54.

2-Naphthylsulfanyl-1,4-benzoquinone (QNS): orange solid, $\mathrm{mp}=132-134{ }^{\circ} \mathrm{C}$, UV $\left(\mathrm{CH}_{3} \mathrm{CN}\right): \lambda_{\max }=420 \mathrm{~nm}\left(\varepsilon=2500 \mathrm{~L} \cdot \mathrm{mol}^{-1} \cdot \mathrm{cm}^{-1}\right)$; ${ }^{1} \mathrm{H}-\mathrm{NMR}\left(\mathrm{CDCl}_{3}\right): \delta=5.87(1 \mathrm{H}, \mathrm{d}, \mathrm{H}-3), 6.65(1 \mathrm{H}$, $\mathrm{dd}, \mathrm{J}=2.4$ and $10.3 \mathrm{~Hz}, \mathrm{H}-5), 6.85(1 \mathrm{H}, \mathrm{d}, \mathrm{H}-6)$, 7.44-8.05(7H, m, naphthyl). ${ }^{13} \mathrm{C}-\mathrm{NMR}\left(\mathrm{CDCl}_{3}\right)$ : 
Table 1. Characteristics of Polymer Samples

\begin{tabular}{|c|c|c|c|c|c|c|c|c|}
\hline \multirow[t]{2}{*}{ Abbreviation $^{\mathrm{a}}$} & \multicolumn{3}{|c|}{ Monomers in Feed (mol\%) } & \multirow{2}{*}{$\begin{array}{l}\text { P.T. }^{\text {b }} \\
\text { (h) }\end{array}$} & \multirow{2}{*}{$\begin{array}{l}\text { Yield } \\
(\%)\end{array}$} & \multirow{2}{*}{$\begin{array}{c}\mathrm{Mn}^{\mathrm{c}} \\
\left(\times 10^{4}\right)\end{array}$} & \multirow{2}{*}{$\frac{\mathrm{Mw}^{\mathrm{c}}}{\mathrm{Mn}}$} & \multirow{2}{*}{$\begin{array}{l}\mathrm{Tg}^{\mathrm{d}} \\
\left({ }^{\circ} \mathrm{C}\right)\end{array}$} \\
\hline & AAPO & AMCO & $\mathrm{St}$ & & & & & \\
\hline $\mathrm{p}[\mathrm{AAPO}(27)-\mathrm{St}]$ & 25 & 0 & 75 & 14 & 51.3 & 8.8 & 1.58 & 87 \\
\hline $\mathrm{p}[\mathrm{AAPO}(42)-\mathrm{St}]$ & 50 & 0 & 50 & 3 & 36.0 & 6.1 & 1.99 & 88 \\
\hline $\mathrm{p}(\mathrm{AAPO})$ & 100 & 0 & 0 & 0.75 & 25.4 & 11.0 & 1.91 & $-{ }^{e}$ \\
\hline $\mathrm{p}[\mathrm{AMCO}(34)-\mathrm{St}]$ & 0 & 30 & 70 & 12 & 52.7 & 12.4 & 2.23 & 89 \\
\hline
\end{tabular}

a) Numbers in parentheses indicate molar fractions in polymers.

b) Polymerization Time.

c) From SEC with polystyrene standard.

d) Obtained from DSC.

e) Not measured.

$\delta=123.85,126.03,127.15,127.88,130.28,130.79$, $133.68,133.90,135.82,136.14,137.44,154.43$, 183.95, 184.36. Calcd for $\mathrm{C}_{16} \mathrm{H}_{10} \mathrm{O}_{2} \mathrm{~S}: \mathrm{C} 72.18, \mathrm{H}$ 3.76. Found: C 72.55, H 3.53 .

2-Benzylsulfanyl-1,4-hydroquinone (hQBS) was obtained by reducing QBS with sodium dithionite in ethanol as ivory powders; ${ }^{1} \mathrm{H}-\mathrm{NMR}$ $\left(\right.$ DMSO- $\left.\mathrm{d}_{6}\right): \delta=4.12\left(2 \mathrm{H}, \mathrm{s}, \mathrm{CH}_{2}\right), 6.54\left(1 \mathrm{H}, \mathrm{s}, \mathrm{H}_{2}\right)$, $7.03(1 \mathrm{H}, \mathrm{s}),, 7.16-7.41(6 \mathrm{H}, \mathrm{m}$, aromatic), 9.35(1H, s, OH), 9.84(1H, s, OH). $\quad \mathrm{UV}\left(\mathrm{H}_{2} \mathrm{O}\right)$ : $\lambda_{\max }=314 \mathrm{~nm}$.

Acetophenone $O$-acryloyloxime (AAPO)[5] and acetophenone N-methacryloyloxyethylcarbamoyloxime (AMCO)[9] were obtained as described in literature. Styrene (St), N,Ndimethylformamide (DMF), toluene, and tetrahydrofuran (THF) were distilled under reduced pressure before use.

Polymers were obtained by radical polymerization. DMF or toluene solutions containing $50 \mathrm{wt} \%$ of monomers and $0.1 \sim 0.25$ wt $\%$ of $\alpha, \alpha^{\prime}$-azobisisobutylonitrile were degassed and heated at $60{ }^{\circ} \mathrm{C}$. The mixture was reprecipitated from methanol after dissolving in THF. The molar fractions of monomer incorporated in copolymers were determined by ${ }^{1} \mathrm{H}-\mathrm{NMR}$ and elemental analysis. Number average molecular weights of polymers were measured by size exclusion chromatography (SEC) on a Jasco GPC equipment consisting of a PU-980 pump, an RI-930 and a Shodex KF-806M column. Glass transition temperature $(\mathrm{Tg})$ was obtained by a Rigaku 8230B differential scanning calorimeter at a heating rate of $10 \mathrm{~K} / \mathrm{min}$. Polymerization conditions and characterization of obtained polymers were listed in Table 1.

Polymer films for IR spectral measurement were prepared by casting their THF solution in a Petri dish and dried gradually in dark. The resulting films were peeled from the dish. Thickness of these films was measured by a Peacock Dial Thickness Gauge. Solubility change was examined by coating THF solutions of the polymers onto silicone plates. The thickness of films was measured by a Nanometrics Nanospec/AFT M3000.

Irradiation was performed by an Ushio UM102 medium-pressure mercury lamp (100 W) through a Toshiba UV-39 filter at room temperature in air. Light intensity was measured by an Orc UV-M02 photometer to be ca. 3 $\mathrm{mW} / \mathrm{cm}^{2}$ around $435 \mathrm{~nm}$. PEB was carried out on a Koike Precision Instrument HM-15G hot plate for $10 \mathrm{~min}$ in air.

Development was performed by soaking the irradiated films in THF for $10 \mathrm{~min}$ at room temperature. Normalized film thickness of polymer films was obtained from ratios of thickness before and after the development.

\section{RESULTS AND DISCUSSION}

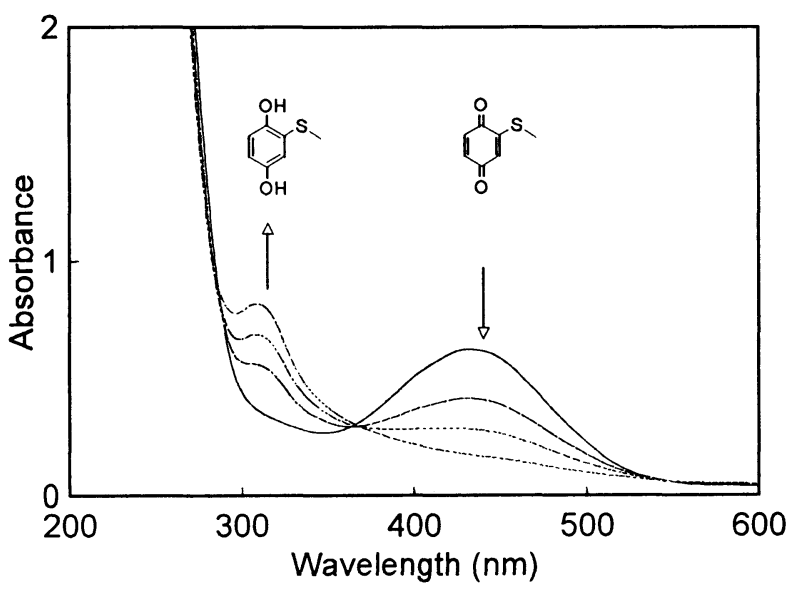

Fig. 1. UV spectral changes for $\mathrm{p}[\mathrm{AAPO}(27)-\mathrm{St}]$ films containing QBS on irradiation for $0,1,5,10 \mathrm{~min}$ (from top to bottom at $420 \mathrm{~nm}$ ). [QBS] : [AOI groups $]=1: 1(\mathrm{~mol} / \mathrm{mol})$. Film thickness; ca. $40 \mu \mathrm{m}$. 


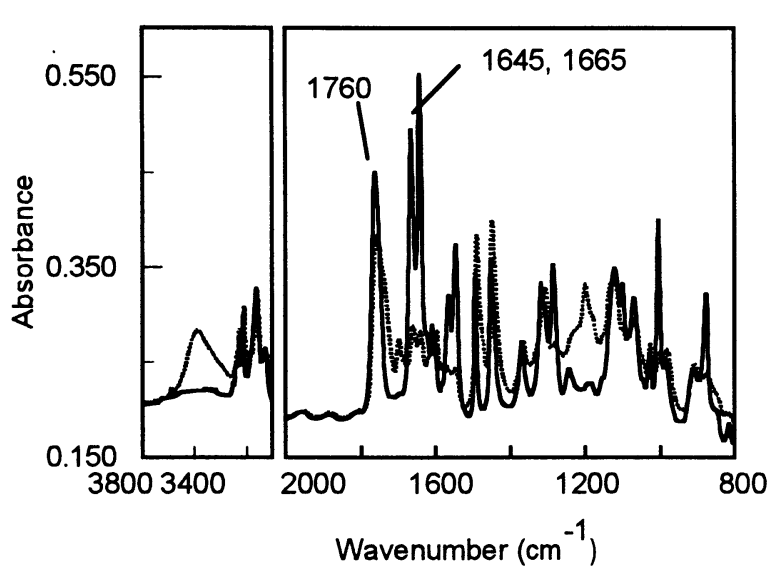

Fig. 2. IR spectral changes for $\mathrm{p}[\mathrm{AAPO}(27)-\mathrm{St}]$ films containing QBS on irradiation for $10 \mathrm{~min}$. [QBS] : [AOI groups] $=1: 1(\mathrm{~mol} / \mathrm{mol})$. Film thickness; ca. 40 $\mu \mathrm{m}$.

Fig. 1 shows UV spectral changes for $\mathrm{p}[\mathrm{AAPO}(27)-\mathrm{St}]+\mathrm{QBS}$ films on irradiation of visible light. The band around $420 \mathrm{~nm}$ due to quinonylsulfanyl moiety decreased, and a new peak appeared at $310 \mathrm{~nm}$. Because hQBS has a maximum peak at $314 \mathrm{~nm}$, the above spectral changes suggest the transformation of QBS into reductive form on irradiation.

IR spectral changes also suggest the transformation of QBS into reductive form. In Fig. 2, the peaks at 1645 and $1665 \mathrm{~cm}^{-1}$ due to $\mathrm{C}=\mathrm{O}$ stretching band in $\mathrm{QBS}$ decreased, and the generation of band were observed around 3400 $\mathrm{cm}^{-1}$ due to hydroxy groups.

Along with these changes of QBS, the decrease of $\mathrm{C}=\mathrm{O}$ absorption band in AOI groups at $1760 \mathrm{~cm}^{-1}$ was also observed. Because there was no change on irradiation of the same polymer film in the absence of QBS, it is apparent that the photolysis of AOI groups was sensitized by QBS.

The photolysis of AOI groups was applied to solubility change of coated films containing these

Table 2. Insolubilization of copolymer films ${ }^{\mathrm{a}}$ on irradiation followed by $\mathrm{PEB}^{\mathrm{b}}$

\begin{tabular}{lccc}
\hline Copolymer & $\begin{array}{c}\text { Additive } \\
\text { Aecomposed } \\
\text { AOI groups (\%) }\end{array}$ & $\begin{array}{c}\text { Insoluble } \\
\text { Fraction (\%) }\end{array}$ \\
\hline p[AAPO(27)-St] & QBS $^{\mathrm{C}}$ & 20 & 0 \\
p[AAPO(42)-St] & QBS $^{\mathrm{C}}$ & 25 & 30 \\
p(AAPO) & QBS $^{\mathrm{C}}$ & 10 & 60 \\
p(AAPO) & benzophenone $^{\mathrm{d}}$ & $10^{\mathrm{e}}$ & 69 \\
\hline
\end{tabular}
a) Film thickness: $0.3 \mu \mathrm{m}$.
b) At $150^{\circ} \mathrm{C}$ for $10 \mathrm{~min}$.
c) $[\mathrm{QBS}]$ : [AOI group] $=1: 1(\mathrm{~mol} / \mathrm{mol})$.
d) [Benzophenone]:[AOI group] $=1: 4.7(\mathrm{~mol} / \mathrm{mol})$.
e) Using $366 \mathrm{~nm}$-light.
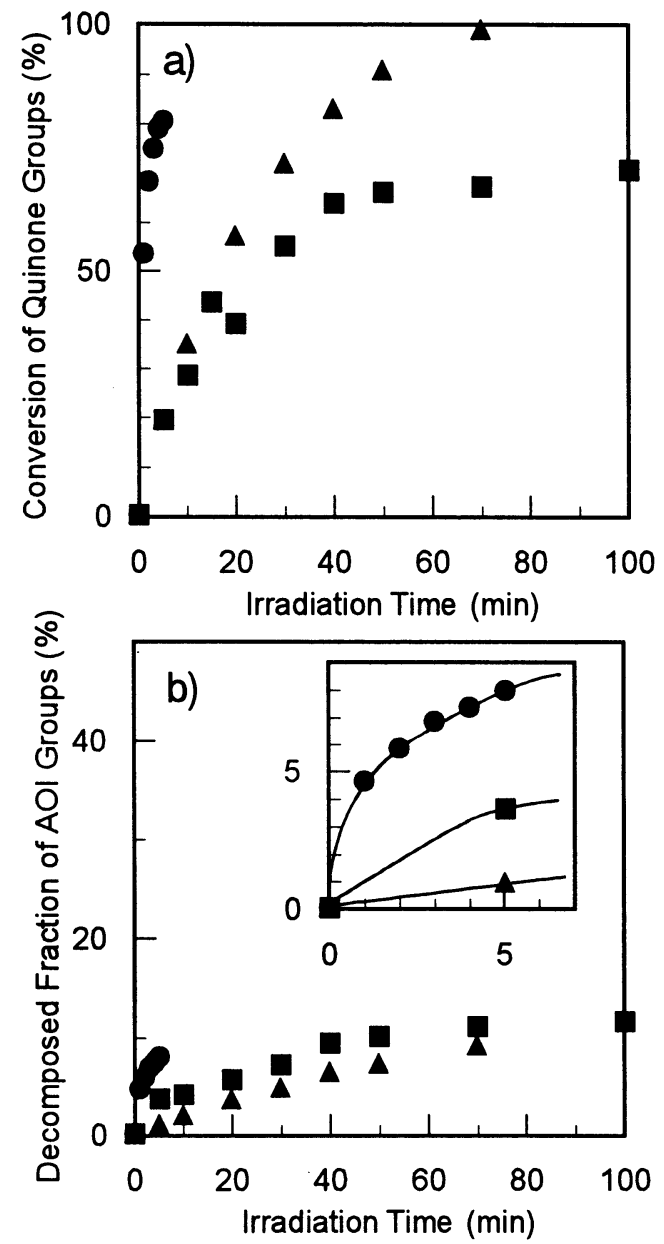

Fig. 3. Photo-reduction of quinones (a) and photolysis of AOI groups (b) in $\mathrm{p}(\mathrm{AAPO})$ films containing QBS( $(\mathbf{0}), \mathrm{QPhS}(\boldsymbol{\square})$, and $\mathrm{QNS}(\boldsymbol{\Delta})$ based on the change of absorbance at 1640 (quinone) and 1760 $\mathrm{cm}^{-1}$ (AOI ) in IR spectra. [Quinone] : [AOI groups] $=1: 8(\mathrm{~mol} / \mathrm{mol})$. Film thickness: $0.3 \mu \mathrm{m}$.

groups into THF. As listed in Table 2, p[AAPO(27)-St] films were soluble even after PEB. However, films of $\mathrm{p}[\mathrm{AAPO}(42)-\mathrm{St}]$ and $\mathrm{p}(\mathrm{AAPO})$ became insoluble. The insoluble fraction of $p(A A P O)$ irradiated visible light in the presence of QBS was nearly the same as that by $366 \mathrm{~nm}$ light in the presence of benzophenone when $10 \%$ of AOI groups were decomposed. This result suggests the formation of amino groups on irradiation of visible light in the presence of QBS.

Photo-reactivity of other quinones in p(AAPO) films are compared in Fig. 3. The reason of the highest reactivity of QBS is not clear at present. In the presence of QBS, the rates of photolysis of AOI groups and insolubilization after PEB were the highest as shown in Fig. 4.

The photolysis of COI groups was also observed on irradiation of visible light in the 


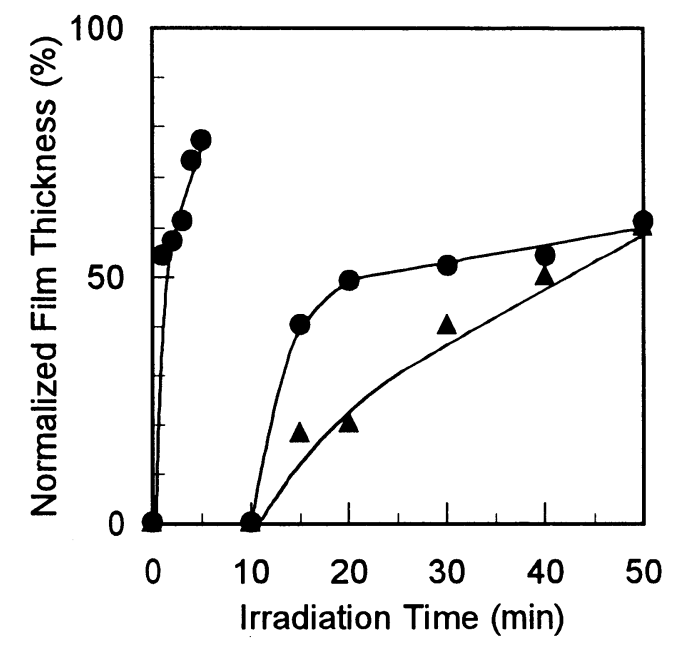

Fig. 4. Insolubilization of $\mathrm{p}(\mathrm{AAPO})$ films containing $\mathrm{QBS}(\boldsymbol{\bullet}), \mathrm{QPhS}(\boldsymbol{\square})$, and $\mathrm{QNS}(\boldsymbol{\Delta})$ on irradiation followed by PEB at $150{ }^{\circ} \mathrm{C}$. Developer: THF. [Quinone] : [AOI groups] $=1: 8(\mathrm{~mol} / \mathrm{mol})$. Film thickness; $0.3 \mu \mathrm{m}$.

presence of QBS. In Fig. 5, peaks at 1495 and $1730 \mathrm{~cm}^{-1}$ due to $\mathrm{C}-\mathrm{N}$ and $\mathrm{C}=\mathrm{O}$ bands decreased, respectively. The change of $U V$ spectra on irradiation was also similar to AAPO copolymers.

Fig. 6 shows the effect of irradiation on the insolubilization of $\mathrm{p}[\mathrm{AMCO}(34)-\mathrm{St}]$ films after PEB treatment. Because COI group is a kind of blocked isocyanate, heat-treatment causes the decomposition of COI group into isocyanate and oxime groups.[10] Thus, even non-irradiated films became insoluble due to the formation of crosslinks between $\mathrm{N}-\mathrm{H}$ and thermally generated isocyanate groups. However, it is clearly that irradiation enhanced the insolubilization.

In conclusion, both $\mathrm{AOI}$ and $\mathrm{COI}$ groups were photolyzed on irradiation of visible light in the presence of benzoquinonylsulfanyl derivatives. Films containing the groups became insoluble after PEB treatment.

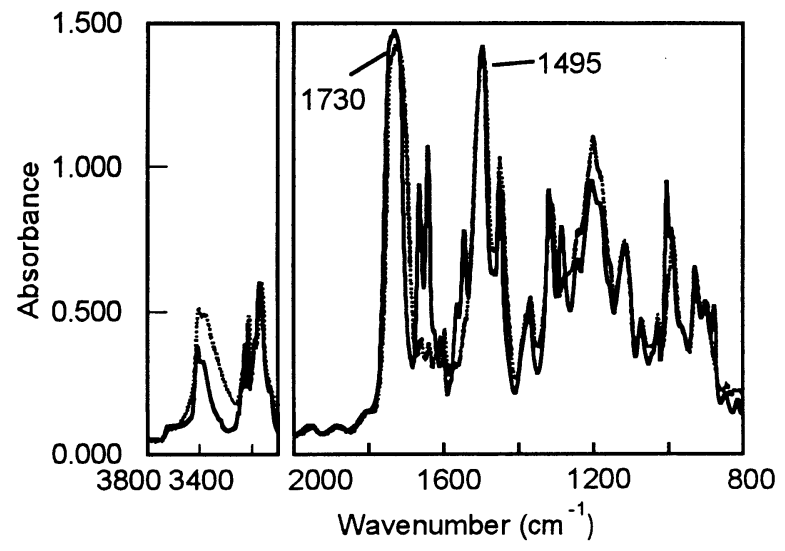

Fig. 5. IR spectral changes for $\mathrm{p}[\mathrm{AMCO}(34)-\mathrm{St}]$ films containing QBS on irradiation for $30 \mathrm{~min}$. [QBS] : [AOI groups] $=1: 2(\mathrm{~mol} / \mathrm{mol})$. Film thickness; ca. $30 \mu \mathrm{m}$.

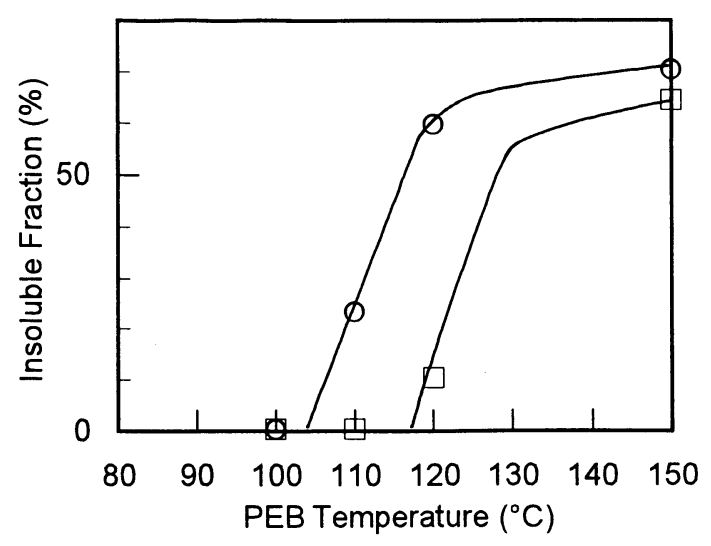

Fig. 6. Effect of irradiation on the insolubilization of $\mathrm{p}[\mathrm{AMCO}(34)-\mathrm{St}]$ films after PEB treatment. Irradiation for $0(\square)$ and $30 \mathrm{~min}(\mathrm{O})$. PEB time; 10 min. [Quinone] : [AOI groups] $=1: 1(\mathrm{~mol} / \mathrm{mol})$. Film thickness; $0.6 \mu \mathrm{m}$.

\section{REFERENCES}

1. For example, "Radiation Curing in Polymer Science and Technology", vol. 4, J. P. Fouassier, J. F. Rabek, Eds., Elsevier Applied Science, London 1993.

2. Y. Cha, M. Tsunooka, and M. Tanaka, J. Photochemistry, 35 (1986) 93.

3. K. Suyama, K. Honma, M. Shirai, and M. Tsunooka, J. Photopolym. Sci. Technol., 13 (2000) 113.

4. K. -H. Song, A. Urano, M. Tsunooka and M. Tanaka, J. Polym. Sci., Part C, Polym. Lett., 25, (1987) 417.

5. K. -H. Song, M. Tsunooka, and M. Tanaka, $J$. Photochem. Photobiol., A; Chem., 44, (1988) 197.

6. X. Allonas, J. Lalevee, J. P. Foussier, H. Tachi, M. Shirai, and M. Tsunooka, Chem. Lett., 2000, (2000) 1090.

7. H. Tachi and M. Tsunooka, Eur. Polym. J. 36 (2000) 2395.

8. K. H. Chae, Macromol. Rapid Commun., 19 (1998) 1.

9. M. Tsunooka, H. Tachi, K Asakino, and K. Suyama, J. Photoscience, 6, (1999) 145.

10. K. Suyama, H. Iriyama, M. Shirai, and $M$. Tsunooka, J. Photopolym. Sci. Technol., 14 (2001) 155

11. K. Suyama, Y. Miyamoto, T. MatsuokaS. Wada, and M. Tsunooka, Polym. Adv. Technol., 11 (2000) 589. 